\title{
EVALUASI NILAI GIZI TEPUNG PISANG GOROHO (Musa acuminate, sp) TERMODIFIKASI
}

\author{
Nutrional Value Evaluation of Modified Goroho Plantain (Musa acuminate, \\ sp. ) Flour \\ Lisa Sangkilen ${ }^{1)}$, Gregoria S.S. Djarkasi ${ }^{1)}$, Lucia C. Mandey ${ }^{1)}$ \\ ${ }^{1)}$ Program Studi Magister Ilmu Pangan \\ Pascasarjana, Universitas Sam Ratulangi \\ Jl. Kampus UNSRAT, Manado95115 \\ e-mail: sangkilenlisa@gmail.com
}

\begin{abstract}
The purpose of this research is to identify the chemical properties of goroho plantain flour produced through the process of modification of coldboiled, cold-steamed and cold-roasted. The method used in this study is the experimental method. The parameters measured were starch content, amylose content, resistant starch content and in vitro digestibility of starch on modified goroho plantain flour. The results obtained in this study were an increase in starch content in cold-boiled treatment $79.29 \%$, cold-steamed $76.83 \%$, cold-roasted $72.86 \%$, amylose content in cold-boiled treatment $25.54 \%$, cold-boiled $24.37 \%$, cold-roasted $21.40 \%$, resistant starch content of cold-boiled treatment $28.87 \%$, cold-steamed $28.18 \%$, cold-roasted $27.21 \%$, and in vitro digestibility cold-boiled treatment $46.17 \%$, cold-boiled $55.66 \%$, cold-roasted $66.12 \%$. The modification of goroho plantain flour with boiled, steamed and roasted treatments can increase the levels of resistant starch in goroho plantain flour.
\end{abstract}

Keywords: goroho banana flour, resistant starch, goroho banana

\section{PENDAHULUAN}

Buah pisang goroho adalah tanaman pisang khas di Sulawesi Utara. Tanaman ini cukup terkenal bagi masyarakat Sulawesi Utara karena memiliki nilai manfaat yang tinggi. Pisang goroho dapat dipanen dengan 2 cara yaitu pada saat bunga mekar dan dapat dilihat pada bentuk buah pisang goroho. Waktu panen pisang goroho pada umur 80-100 hari. Panen yang tidak terlalu tua atau tingkat kematangan 75$80 \%$ memiliki nilai kadar pati yang maksimum dan juga memiliki penyimpanan yang cukup lama. Beberapa penelitian telah dilakukan dalam pemanfaatan pisang goroho, seperti dalam penelitian Sayangbati (2012) yang membuat biskuit berbahan baku tepung pisang goroho dan Djarkasi dkk., (2010) yang mengkaji penggunaan tepung pisang 
goroho sebagai subtitusi dalam pembuatan roti tawar. Ini menunjukkan bahwa tepung pisang goroho dapat digunakan dalam pembuatan kue kering.

Rosida dan Rosida (2011) menyatakan bahwa salah satu sumber pati resisten adalah pisang karena kandungan pati pisang cukup tinggi (28-29\%) sehingga merupakan sumber yang potensial. Hasil penelitian sebelumnya yang dilakukan Rosida (2011) menunjukan bahwa perlakuan pemasakan yang dikombinasi pendinginan dapat meningkatkan kadar pati resisten pisang, terutama perlakuan perebusanpendinginan, pengukusan-pendinginan, dan pemanggangan-pendinginan pada pisang tanduk dan pisang raja nangka. Tulisan ini memaparkan hasil penelitian analisis tepung pisang goroho termodifikasi dengan perlakuan rebus, kukus dan panggang.

\section{METODOLOGI PENELITIAN}

Bahan-bahan yang digunakan dalam penelitian ini terdiri dari pisang goroho dengan tingkat kematangan $80 \%$ atau pisang yang berumur 90 sampai 93 hari sebelum panen. Pisang goroho yang akan digunakan diperoleh dari perkebunan yang ada di kecamatan Sonder. Bahan bahan kimia yang digunakan adalah $\mathrm{KOH}$, akuades, $\mathrm{HCl}, \mathrm{NaOH}, \mathrm{H}_{2} \mathrm{SO}_{4}$ pekat, amilosa murni, etanol, larutan asetat, alatalat yang digunakan dalam penelitian ini terdiri dari ayakan 80 mesh, alat penggiling (grinder), penangas air, inkubator, timer, alkohol, spuit $(3 \mathrm{ml})$, refrigerator, sentrifuse, kuvet, strip, dan alat-alat gelas kimia di gunakan sebagai alat untuk analisis. Pisang goroho dicuci dan dikeringkan, setelah itu pisang goroho dikupas dan dipotong $\pm 2 \mathrm{~mm}$, setelah itu masuk dalam proses modifikasi dengan perlakuan yang pertama yaitu pisang direbus pada suhu $100^{\circ} \mathrm{C}$ selama 15 menit, kedua dikukus pada suhu $100^{\circ} \mathrm{C}$ selama
15 menit, ketiga dipanggang pada suhu $100^{\circ} \mathrm{C}$ selama 15 menit. Setelah itu dilakukan pendinginan pada suhu $15^{\circ} \mathrm{C}$ selama 24 jam, lalu dilakukan pengeringan pada suhu $60^{\circ} \mathrm{C}$ selama 6 jam. Selanjutnya penggilingan pisang goroho dan pengayakan 80 mesh dan selesai pengayakan dihasilkan tepung pisang goroho termodifikasi dengan 3 perlakuan. Prosedur modifikasi ini mengacu pada laporan hasil penelitian Rosida (2010). Tepung pisang goroho termodifikasi dianalisis menggunakan alat spektrofotometer pada $750 \mathrm{~nm}$. Analisis kandungan kadar pati, kadar amilosa, kadar pati resisten dan daya cerna in vitro dilakukan terhadap tepung pisang goroho termodifikasi rebus-dingin (Sampel A), termodifikasi kukus-dingin (Sampel B), termodifikasi panggang-dingin (Sampel C).

\section{HASIL DAN PEMBAHASAN}

\section{Kadar Pati Tepung Pisang Goroho}

Hasil analisis kadar pati tepung pisang "goroho" tertinggi yang dihasilkan berdasarkan perlakuan termodifikasi diperoleh pada perlakuan rebus-dingin yaitu sebesar $79.29 \%$, sedangkan kadar pati nilai terendah diperoleh pada perlakuan termodifikasi panggang-dingin yaitu sebesar $72.86 \%$. Pati adalah karbohidrat yang merupakan polimer glukosa, dan terdiri atas amilosa dan amilopektin (Jacobs dan Delcour 1998). Pati berperan sebagai sumber makanan penghasil energi utama dari golongan karbohidrat. Kadar pati merupakan salah satu kriteria mutu untuk tepung, baik sebagai bahan pangan maupun bahan nonpangan. Menurut Nurhayati $d k k .2014$ bahwa dalam proses pemanasan pati akan terpecah dan tergelatinisasi, selanjutnya juga amilosa akan teretrogradasi pada saat pendinginan. Faktor perlakuan pemanasan pada tepung pisang sangat berpengaruh terhadap kadar pati. Pada Tabel 3 menunjukan bahwa perlakuan pada 
tepung pisang dengan cara rebus-dingin memiliki kadar pati yang sangat tinggi dibandingkan dengan kukus-dingin dan panggang-dingin. Hal ini disebabkan karena pemanasan mereduksi kandungan pati yang akibatnya gelatinisasi pada pati yang kemudian meyebabkan substansi kerusakan pada pati yang menunjukan penurunan kadar pati pada tepung pisang. Nilai rata-rata kadar pati tepung pisang "goroho" termodifikasi dapat dilihat pada Tabel 1.

Tabel 1. Nilai rata-rata kadar pati tepung pisang "goroho" termodifikasi

\begin{tabular}{ll}
\hline Perlakuan & Rata-rata $(\%)$ \\
\hline A (Rebus) & $79.29 \pm 1.02$ \\
B (Kukus) & $76.83 \pm 0.88$ \\
C (Panggang) & $72.86 \pm 0.65$ \\
\hline
\end{tabular}

\section{Kadar Amilosa}

Berdasarkan hasil analisis terhadap kadar amilosa dari hasil proses tepung pisang goroho termodifikasi sangat berpengaruh nyata dengan perlakuan rebus-dingin, kukus-dingin dan panggangdingin. Nilai rata-rata kadar amilosa tepung pisang goroho termodifikasi dapat dilihat pada Tabel 2.

Tabel 2. Nilai rata-rata kadar amilosa tepung pisang goroho termodifikasi

\begin{tabular}{ll}
\hline Perlakuan & Rata-rata $(\%)$ \\
\hline A (Rebus) & $25.54 \pm 0.77$ \\
B (Kukus) & $24.37 \pm 0.40$ \\
C (Panggang) & $21.40 \pm 0.03$ \\
\hline
\end{tabular}

Dari Tabel 2 menunjukan bahwa perlakuan rebus-dingin berpengaruh terhadap kadar amilosa. Hal ini disebabkan karena kadar amilosa dari tepung pisang yang dihasilkan dengan proses perlakuan rebus-dingin belum terjadi degradasi amilosa. Hal ini juga ditunjukan pada proses perlakuan termodifikasi dari tepung pisang dengan perlakuan kukus-dingin dan panggangdingin, meskipun adanya penurunan sedikit tetapi masih bias membuktikan bahwa tepung pisang yang dihasilkan masih memiliki potensi yang sangat baik dalam menghasilkan pati resisten. Kadar amilosa hasil perlakuan termodifikasi sedikit mengalami penurunan, meskipun relative masih tetap sama. Penurunan kadar amilosa terjadi karena adanya penurunan suhu gelatinisasi dari granula pati (Abdilah, 2010).

\section{Kadar Pati Resisten}

Hasil analisis yang dilakukan perlakuan rebus-dingin, kukus-dingin dan panggang dingin sangat berpengaruh terhadap kadar pati resisten. Perlakuan rebus-dingin pada suhu $100^{\circ} \mathrm{C}$ dan didingin pada suhu ruang $15^{\circ} \mathrm{C}$ selama 24 jam dapat meningkatkan kandungan pati resisten tepung pisang "goroho". Kandungan pati resisten tertinggi diperoleh dengan perlakuan rebus-dingin yaitu $28.87 \%$. Sedangkan kadar pati resisten terendah diperoleh pada perlakuan panggang-dingin yaitu $27.21 \%$. Nilai rata-rata kadar pati resisten tepung pisang "goroho" termodifikasi dapat dilihat pada tabel 3

Perlakuan rebus-dingin dapat meningkatkan kadar pati resisten pada tepung pisang "goroho" termodifikasi. Hal ini dikarenakan selama proses pendinginan, enzim $\alpha$-amilase yang telah dihasilkan mikroba amilolitik akan memecahkan ikatan $\alpha-1,4$ glikosidik pada pati sehingga rantai amilosa dan amilopektin menjadi rantai yang lebih pendek. Dan juga selain itu asam-asam organil yang telah dihasilkan oleh bakteri asam laktat (BAL) akan meghidrolisis pati. Sehingga jumlah amilosa yang lebih banyak dengan derajat polimerisasi lebih rendah akan lebih mudah membentuk kristalin yang bersifat resisten selama proses retrogradasi setelah pemanasan. Oleh karena itu jumlah pati resisten yang akan terbentuk akan lebih semakin tinggi. 
Tabel 3. Nilai rata-rata kadar pati esisten tepung pisang "goroho" termodifikasi

\begin{tabular}{ll}
\hline Perlakuan & Rata-rata $(\%)$ \\
\hline A (Rebus) & $28.87 \pm 0.08$ \\
B (Kukus) & $28.18 \pm 0.03$ \\
C (Panggang) & $27.21 \pm 0.11$ \\
\hline
\end{tabular}

Selama proses retrogradasi dengan jumlah amilosa yang lebih banyak maka pati akan lebih mudah membentuk kristalin yang resisten (Onyango $d k k$. 2006). Thompson (2000) amilosa akan lebih mudah membentuk ikatan hydrogen selama retrogradasi sehingga strukturnya akan menjadi lebih stabil sedangkan amilopektin lebih sulit membentuk ikatan hidrogen selama retrogradasi dan struktur yang dibentuknya lebih tidak stabil.

Kadar pati resisten pada tepung pisang sangat berhubungan dengan kadar amilosa yang berasal dari bagian pendek amilopektin ( Rohma, 2010). Dalam pembentukan pati resisten oleh pemanasan dan pendinginan dipengaruhi oleh kristalisasi amilosa, sehingga kadar amilosa yang ada akan terjadi perubahan, oleh karena itu pati resisten yang telah terbentuk akan mengalami perubahan. Terjadinya peningkatan kadar pati resisten seperti dengan hasil penelitian Nurhayati (2014) melaporkan bahwa modifikasi proses perlakuan fermentasi $(0,12,24,36$, $48,60,78$ jam) dan pemanasan yang bertekanan pendinginan menggunakan autoklaf pada suhu $\left(121^{\circ} \mathrm{C}\right.$ selama 15 menit) dengan perlakuan yang optimal fermentasi spontan selama 24 jam dimana mampu meningkatkan kadar pati resisten dan amilosa tepung pisang var agung sumeru hingga empat kali lipat ( 10,32\% menjadi $42,68 \%$ berat kering pati).

\section{Daya Cerna Pati in Vitro}

Hasil analisis sidik ragam perlakuan rebus dingin, kukus-dingin dan panggang dingin memiliki pengaruh terhadap daya cerna pati tepung pisang goroho termodifikasi. Perlakuan rebus- dingin memiliki nilai daya cerna pati yang paling rendah dengan nilai rata-rata $46.17 \%$ dan nilai daya cerna pati paling tinggi terdapat pada perlakuan panggangdingin dengan nilai rata-rata $66.12 \%$. Hal ini menunjukan bahwa setiap perlakuan yang dilakukan pada tepung pisang goroho termodifikasi memiliki nilai daya cerna pati yang berbeda juga. Pengukuran daya cerna pati in vitro dilakukan untuk melihat tingkat kemudahan suatu jenis pati untuk dapat dihidrolisis oleh enzim-enzim pemecah pati untuk menjadi unit-unit yang lebih kecil. Daya cerna pati yang rendah menunjukkan bahwa pati sulit untuk dicerna yang kemungkinan pada pati tersebut terdapat komponen yang sulit atau tidak dapat dicerna. Pada proses modifikasi tepung pisang dapat mempengaruhi daya cerna pati in vitro pada tepung pisang yang akan dihasilkan.

Pati tahan cerna ditemukan pertama kali oleh Englyst $d k k$. , (1982) dan didefinisikan sebagai fraksi pati yang tahan terhadap hidrolisis enzim pencernaan amilase dan perlakuan pulunase secara in vitro. Karena pati banyak dijumpai dalam saluran pencernaan serta sedikit difermentasi oleh mikroflora usus, pati resisten sering diidentifikasi sebagai fraksi pati makanan yang sulit dicerna di dalam usus halus sehingga memiliki fungsi untuk kesehatan. Pati resisten memiliki sifat seperti halnya serat makanan, sebagian serat bersifat tidak larut dan sebagian lagi merupakan serat yang larut (Asp, 1992). Nilai rata-rata daya cerna pati in vitro tepung pisang goroho termodifikasi dapat dilihat pada tabel 4 .

Tabel 4. Nilai rata-rata daya cerna pati in vitro tepung pisang "goroho" termodifikasi

\begin{tabular}{ll}
\hline Perlakuan & Rata-rata (\%) \\
\hline A (Rebus) & $46.17 \pm 0.56$ \\
B (Kukus) & $55.66 \pm 1.36$ \\
C (Panggang) & $66.12 \pm 0.65$ \\
\hline
\end{tabular}


Dari tabel 4 telah dijelaskan hasilhasil yang telah didapat sesuai dengan perlakuan masing-masing. Dimana hasil perlakuan tepung pisang "goroho" termodifikasi rebus-dingin yaitu $46.17 \%$, kukus-dingin $55.66 \%$, dan panggang dingin yaitu $66.12 \%$. Hasil analisis daya cerna pati yang didapatkan menunjukan bahwa perlakuan-perlakuan yang dibuat terdapat pengaruh yang nyata terhadap daya cerna pati in vitro tepung pisang goroho termodifikasi yang dihasilkan.

Sebagai pembanding yang terkait penerapan tepung pra-masak pisang tanduk dan pisang raja nangka yang dilaporkan oleh Rosida (2010) bahwa dengan adanya modifikasi terhadap tepung pra-masak pisang tanduk dan pisang raja nangka dengan perlakuan rebus, kukus dan panggang dapat meningkatkan kadar pati resisten yang dapat memberikan efek penurunan gula darah pada tikus. Penelitian ini patut dilanjutkan dengan uji in vivo, seperti uji antihiperglikemik.

\section{KESIMPULAN}

Analisis sifat kimia tepung pisang goroho termodifikasi dengan proses rebusdingin menghasilkan nilai kadar pati yang sangat tinggi yaitu $79.29 \%$, dibandingkan dengan tepung pisang goroho termodifikasi dengan proses kukus-dingin dan panggang-dingin yaitu dengan nilai yang lebih rendah $76.83 \%-72.86 \%$, kadar amilosa $25.54 \%-21.40 \%$, kadar pati resisten $28.87-27.21 \%$, dan daya cerna pati in vitro hasil perlakuan tepung pisang "goroho" termodifikasi rebusdingin yaitu $46.17 \%$, kukus-dingin 55.66 $\%$, dan panggang dingin yaitu $66.12 \%$. Jadi proses modifikasi tepung pisang goroho dengan perlakuan rebus-dingin, kukus-dingin dan panggang-dingin dapat meningkatkan kadar pati, kadar amilosa, kadar pati resisten dan daya cerna in vitro.

\section{DAFTAR PUSTAKA}

Asp, N-G, dan I. Bjorck. 1992. Resistant Starch A Review. Trends in Food Science and Technology. Vol 3 : 111-114.

Abdillah, F. 2010. Modifikasi Tepung Pisang Tanduk (Musa paradisiaca Formatypica) Melalui Proses fermentasi Spontan dan Pemanasan otoklaf Untuk Meningkatkan Kadar Pati Resisten (Tesis). Bogor. Program Pascasarjana Institut Pertanian Bogor.

Djarkasi S., M. F. Sumual, L. Lalujan, K. Kapahang. $\quad 2010 . \quad$ Kajian Penggunaan Tepung Pisang Goroho (Musa paradisiacal forma typical) Sebagai Bahan Suptitusi Dalam Pembuatan Roti Tawar. Jurnal Teknologi Pertanian. 5 (2) $: 1-7$

Englyst, H. N., S. M. Kingman, J. H. Cummings. 1982. Classification and Measurement of Nutritionally Important Starch Fractions. In Impact of Analytical Method on Resistant Starch Determination. http://www. optaFood.com/access/rsm. html. pp1-6

Jacobs, H. dan J.A. Delcour. 1998. Hydrothermal modifications of granular starch with retention of the granular structure: Review. J. Agric. Food Chem. 46(8): 2895-2905.

Nurhayati, B. S. Laksmini, Widowati, Kusumaningrum. 2014.

Komposisi Kimia dan Kristalintas Tepung Pisang Termodifikasi Secara Fermentasi Spontan dan Siklus Pemanasan Bertekanan Pendinginan. Jurnal AGRITECH, Vol.43, No 2.

Onyango C., T. Bley, A. Jacob, T. Henle, H. Rohm. 2006. Influence of Incubation Temperature and Time on Resistant Starch Type III Formation from Autoclaved and 
Acid-hydrolysed Cassava Starch. Carbohydrate Polymers 66: 494499.

Rohma M. 2014. Perubahan Komposisi

Pati Pada Tepung Pisang Kapas (Musa comiculata) Termodifikasi Secara Fermentasi Spontan dan Lama Pemanasan BertekananPendinginan. Prosiding Seminar Nasional Kimia. HKI-Kaltim. ISBN:978-602-19421-0-9.

Rosida. 2008. Evaluasi Nilai Gizi Pati Resisten Pisang (Kajian Varietas Pisang dan Proses Pengolahan). Laporan Hasil Penelitian Tahun Pertama Hibah Bersaing TA. 2008.

Sayangbati F., E. Nuraly, L. Mandey, M. Lelemboto. 2012. Karakterisrik Fisikokimia Biskuit Berbahan Baku Tepung Pisang Goroho (Musa acuminate,sp). Skripsi Fakultas Pertanian. Unsrat. Manado.

Thompson D. B. 2000. On the NonRandom Nature of Amylopectin Branching. Carbohydrate Polymers 43: 223-239. 